\title{
MULTI SENSOR AND PLATFORMS SETUPS FOR VARIOUS AIRBORNE APPLICATIONS
}

\author{
G.Kemper ${ }^{\mathrm{a}}$, R. Vasel ${ }^{\mathrm{b} *}$ \\ ${ }^{a}$ GGS GmbH,Speyer / Germany - kemper@ggs-speyer.de \\ b Aerial SurveyS GmbH /Germany - rv@aerialsurveys.de
}

\section{Commission I, WG I/3}

KEY WORDS: Multi Sensor, Thermal, Application

\begin{abstract}
:
To combine various sensors to get a system for specific use became popular within the last 10 years. Metric mid format cameras meanwhile reach the $100 \mathrm{MPix}$ and entered the mapping market to compete with the big format sensors. Beside that also other sensors as SLR Cameras provide high resolution and enter the aerial surveying market for orthophoto production or monitoring applications. Flexibility, purchase-costs, size and weight are common aspects to design multi-sensor systems. Some sensors are useful for mapping while others are part of environmental monitoring systems. Beside classical surveying aircrafts also UL Airplanes, Para/Trikes or UAVs make use of multi sensor systems. Many of them are customer specific while other already are frequently used in the market. This paper aims to show some setup, their application, what are the results and what are the pros and cons of them are.
\end{abstract}

\section{DUAL/TRIPLE MAPPING CAMERA SETUP:}

Wide area mapping to generate orthophotos either requests a big format sensor or alternatively a setup with 2 or 3 mid-format cameras that can be used for ultra wide corridors. In order to save flight lines for a mapping project in the desert area of Sudan, a system using 3*80 MPIX Phase One IXA 180 Cameras, each with a $150 \mathrm{~mm}$ lens, was designed. With an overlap of $20 \%$ between the single images, a synthetic frame of $26.800 * 7.752$ pixels was achieved. Thus, even bigger than the upcoming DMC-3, a good image quality due to $5.2 \mu \mathrm{m}$ pixel size can be expected. The long focal length and the short forward length result in a low vertical resolution and limit the use for 3D mapping. Nevertheless for Orthophoto-production the extraction of the DTM is sufficient and gives at a GSD of 10 $\mathrm{cm}$ an average accuracy of $32 \mathrm{~cm}$ in height.
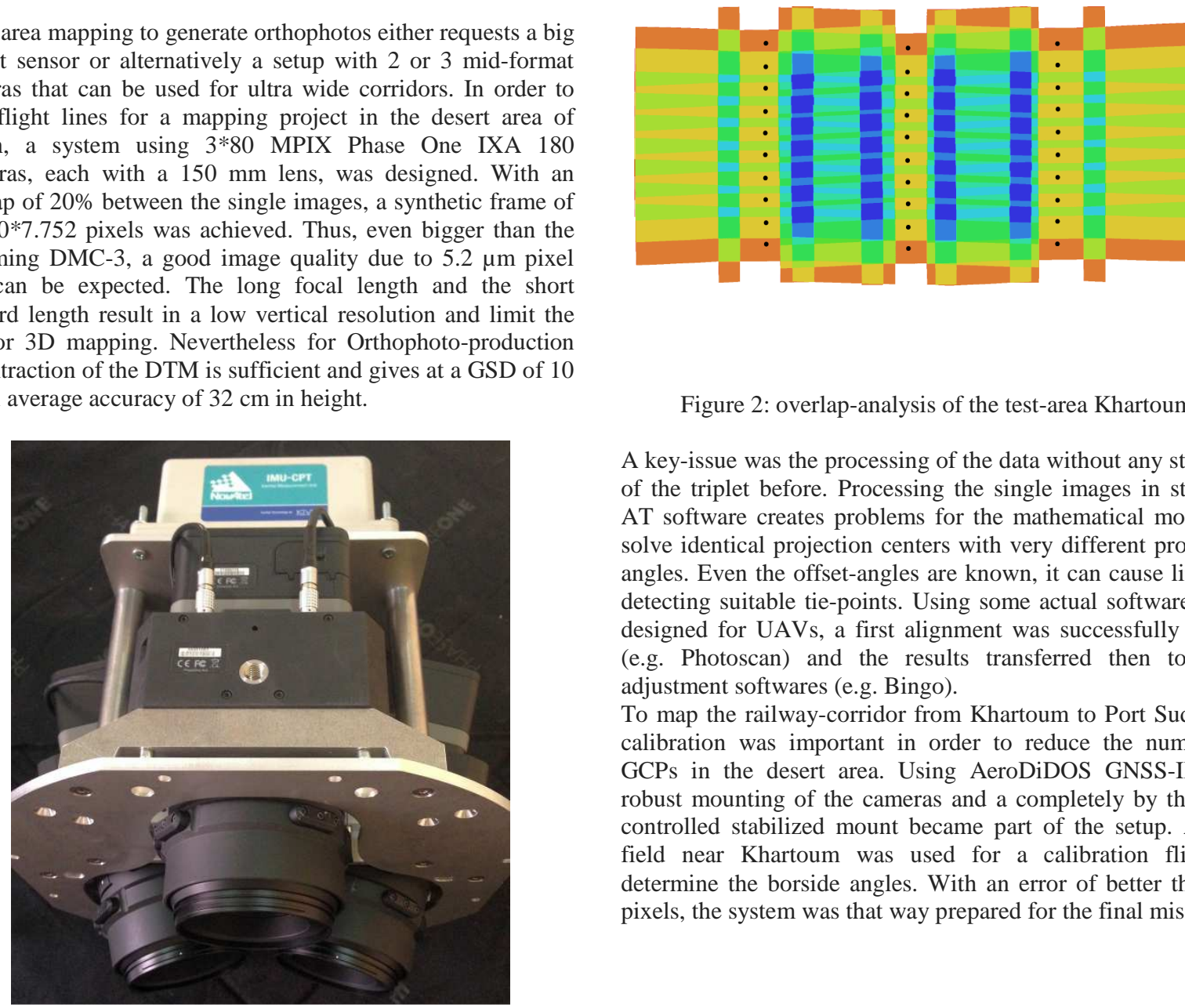

Figure 2: overlap-analysis of the test-area Khartoum

A key-issue was the processing of the data without any stitching of the triplet before. Processing the single images in standard AT software creates problems for the mathematical models to solve identical projection centers with very different projection angles. Even the offset-angles are known, it can cause limits in detecting suitable tie-points. Using some actual software tools, designed for UAVs, a first alignment was successfully solved (e.g. Photoscan) and the results transferred then to other adjustment softwares (e.g. Bingo).

To map the railway-corridor from Khartoum to Port Sudan the calibration was important in order to reduce the number of GCPs in the desert area. Using AeroDiDOS GNSS-IMU, a robust mounting of the cameras and a completely by the IMU controlled stabilized mount became part of the setup. A testfield near Khartoum was used for a calibration flight to determine the borside angles. With an error of better than 0.5 pixels, the system was that way prepared for the final mission.

Figure 1: setup of a camera-triple with GNSS-INS 


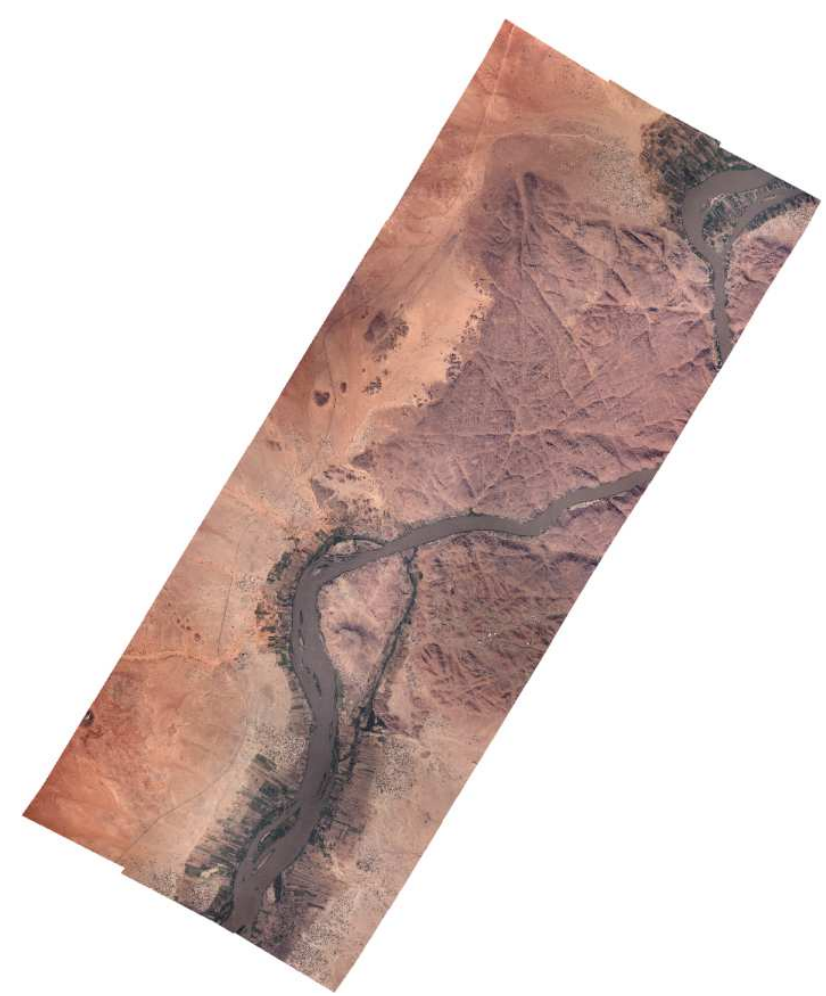

Figure 3: Orthophoto-mosaic of the Wad al Basal area Orthophoto and a core DTM were the final products that delivered a robust and good result.

\section{MULTI CAMERA FOR SEABIRD MONITORING}

One system was created to support environmental monitoring in very high resolution of $2 \mathrm{~cm}$ GSD to identify and count seabirds. Not high accurate geometric images were major goal for this application, the optimal image quality and a big number of observations have been the main target. Two Phase One IXA cameras with $110 \mathrm{~mm}$ lens defined the optimal flight height in order not disturbing the birds, still to be able o fly below the clouds and to be higher than the rotors of off-shore wind farms. Both cameras make use of FMC for the $2 \mathrm{~cm}$ GSD and were mounted with only $5 \%$ overlap on a gyro-stabilized mount. Fast data capturing was achieved with a special computer rack designed for the fastest possible data transfer. The GPS accuracy of $2 \mathrm{~cm}$ and the attitude of about 0.5 degree are fine enough for a proper geo-localization of the birds. Using a special tool preselect images with and without objects automatically to assist the semi-automated following workflow. The problem of glare effects is planned to be adjusted by using a third camera in the NIR band.

In a new project the implementation of GNSS-INS to get better direct referenced images will help in a better image to image correlation especially if the NIR will be used for the glare compensation. That way, a better algorithm to detect birds on the images can be expected to make a automated data-extraction possible

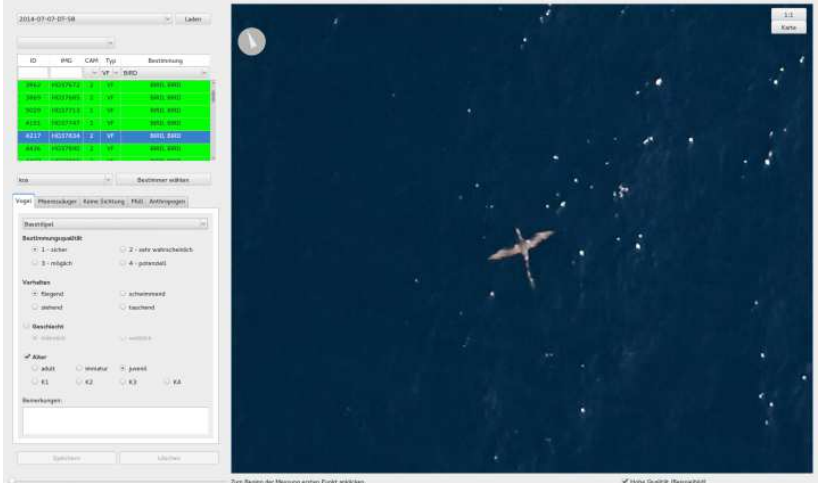

Figure 4: Screen shot of a software interface used for species identification (example image shows a juvenile gannet)

3.

\section{AGRICULTURAL APPLICATION}

For the scientific research AirAgro a setup for agricultural monitoring by using modified SLR cameras to detect the red edge in the NIR bands has been created. Due to financial limitations, the system was designed most cost-effectively and just equipped with a Dual frequency GNSS receiver. As a master camera a Rollei Metric 25 MPix camera (P25) as RGB was used with additional 2 modified Nikon SLR cameras that captured images in NIR. In that case, the metric camera was used as a master while the others were co-registered. The resulted accuracy in co-registration was better than 1 pixel while the relative accuracy between the images was about $1 / 4$ of a pixel.

The Nikon cameras use a bayer pattern which is not equally sensitive in the NIR. Using homogeneous NIR areas, a balancing the Bayer pattern and the vignetting of the lenses was done before entering the AT and ortho-rectification. That way a quantitative analysis of the chlorophyll activity was possible.

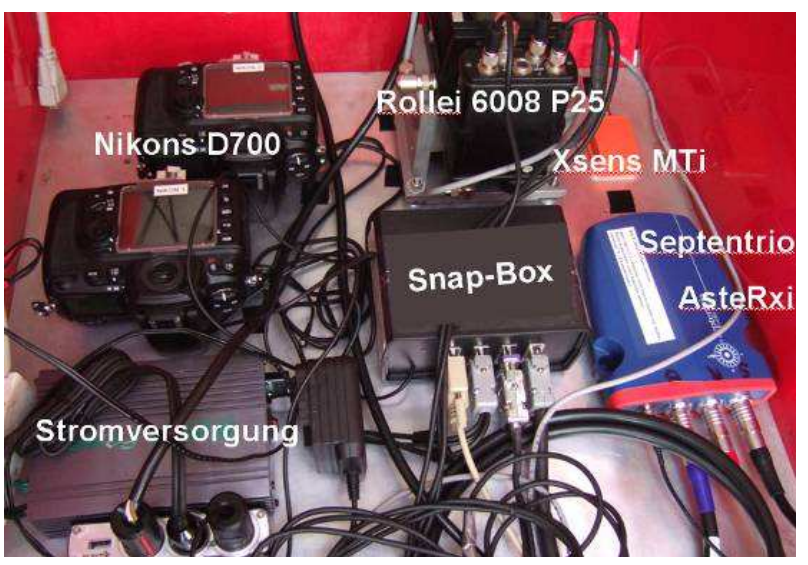

Figure 5: Setup of a metric RGB Camera and 2 modified Nikon for capturing images in the NIR red edge spectrum 


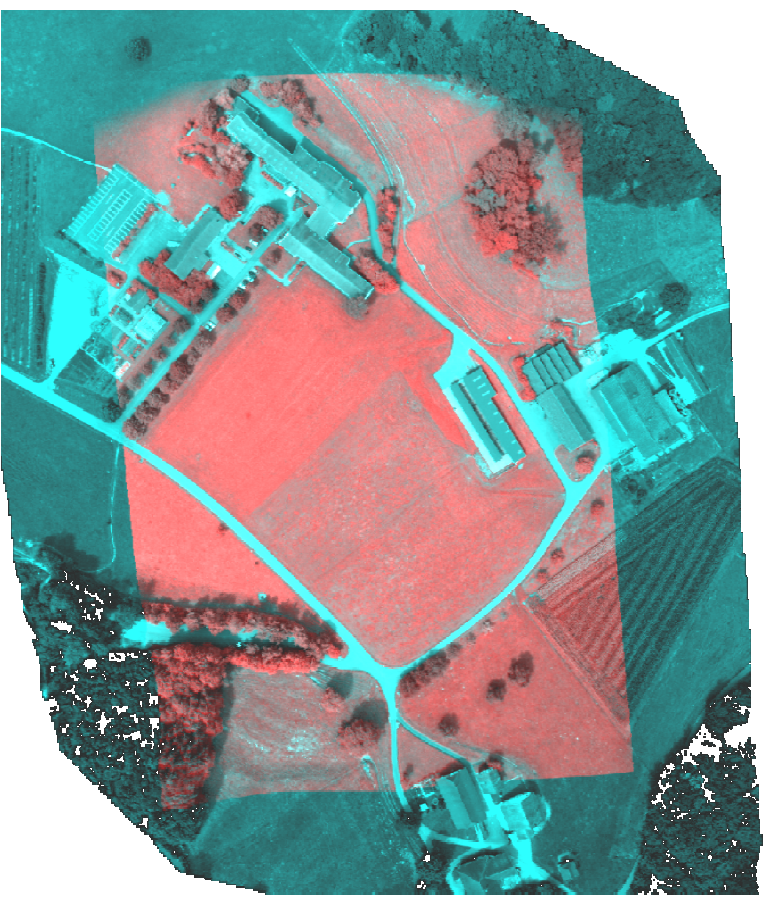

Figure 6: CIR image generation from the RGB Master camera and the NIR Nikon images after co-registration.

\section{RGB AND THIR CAMERASYSTEM}

Thermal sensors measure thermal emissions in the wavelength of $7.5-14 \mu \mathrm{m}$. The relative thermal sensitivity of such sensors is very good while the absolute received temperature information is depended on many factors e.g. emissivity, surface structure, athmospheric absorption.... Finally the search for anomalies is the typical goal. One sensor-combination was made for water and/or humidity detection in the environment especially soils. The combination of a thermal sensor with an RGB camera is not very common because RGB is a typical daylight camera application while Thermal data usually are captured in the nighttime. However, during daytime you also get results with a thermal camera that must be interpreted in a different way. Temperature differences can be detected due to the absorption of materials (e.g. dark soils), from the inclination (south oriented roofs or hills) and materials that accumulate heat in a specific way. Besides that, water in soils or the environment causes heat loss due to evapo-transpiration while open water reacts as a huge accumulator. For the proper interpretation, you then make use of the RGB image. That way, you can detect humid and dry soils and also water infiltration in artificial structures (bridges...).

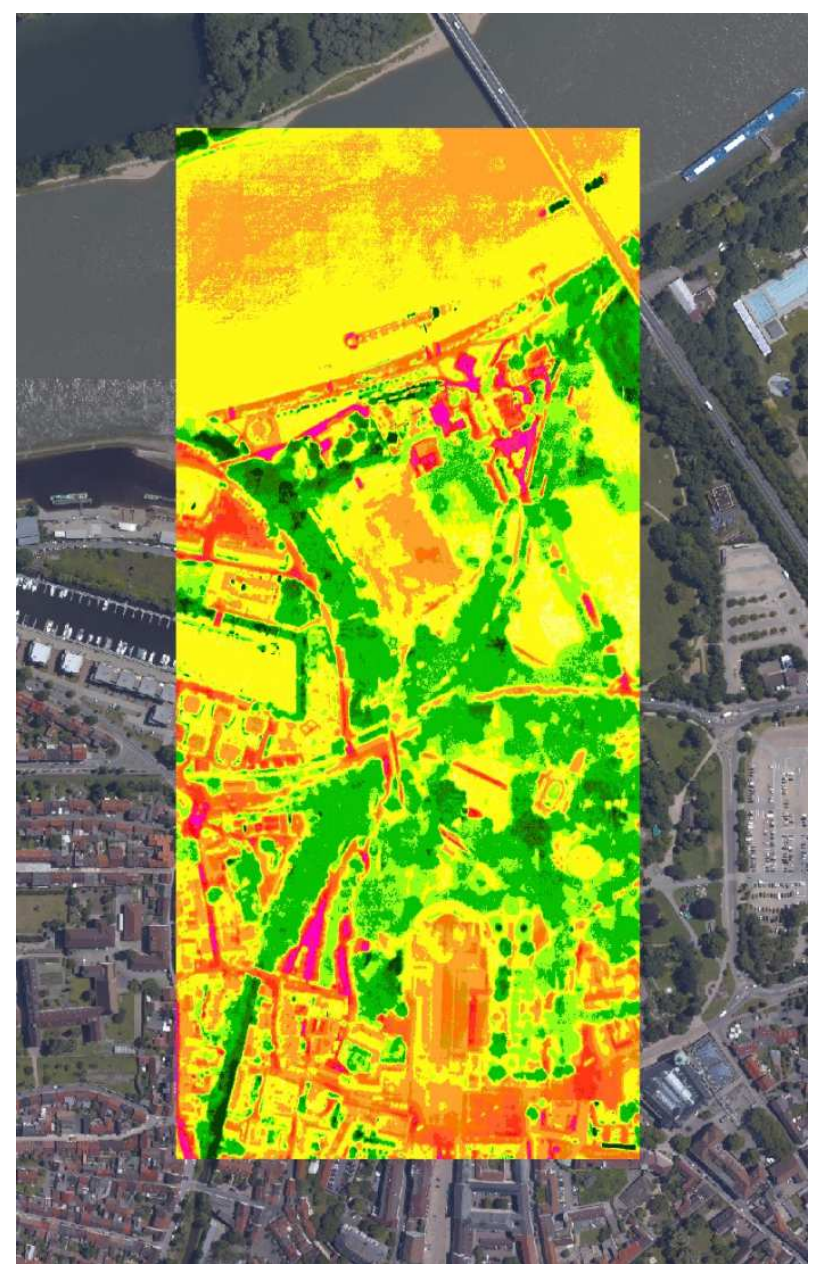

Figure 7: Thermal image overlaid over an Orthophoto of a daytime survey for monitoring city climate. Green areas close to water bodies reduce the temperature by transpiration. 


\section{OBLIQUE IMAGING}

Oblique imaging became very popular within the last years even that way of capturing images was already used since many decades. Besides architectural oblique imaging, also for open mining and other special tasks oblique images were used for a long time. About 8 years ago, there was a higher request for such data, either for homeland-security issues or for internet applications as Bing, Virtual Earth, Google, city planning and others. Cameras mounted between 30 and 50 degrees off nadir are typically defined as oblique. With some exceptions, a core georeference to display the data on the approximate place over a map was sufficient. Besides that, the image quality and resolution of the cameras was poor that time. The use of such data was situated in specific segments only.

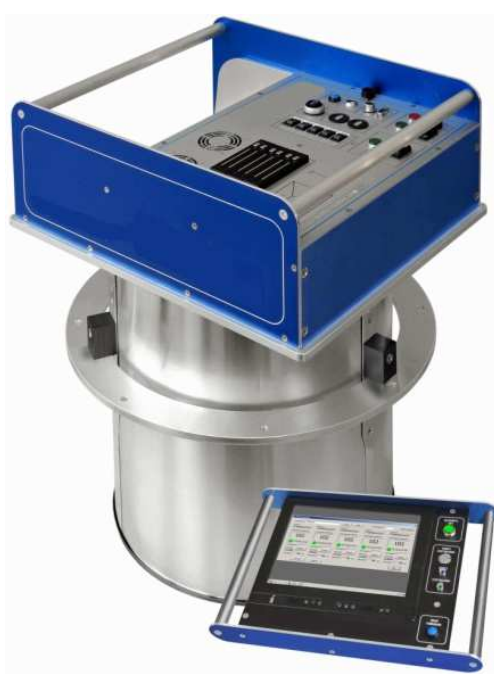

Figure 8: Oblique Imager based on SLR Cameras

Actually we can make use of SLR Cameras that capture images with $36-50$ MPix that give a remarkable result. GGS designed an Oblique Imaging System based on 5 Nikon D800E cameras and $50 \mathrm{~mm}$ focal length. First task was the mounting of the cameras under 40 degree angle beside the nadir camera which is that stabile that the relative tilt angles can be used directly in the image orientation as relatives or by using GNSS-INS as absolute values once the system is calibrated. In the case that these cameras cannot be managed to operate $100 \%$ simultaneously, this causes problems when using direct referencing devices. For that reason, a Multi Snap controller that systematically delays the single cameras solves this issue so that finally each event is separated and related to each single camera. This asynchronous device is patented and has been tested successfully.

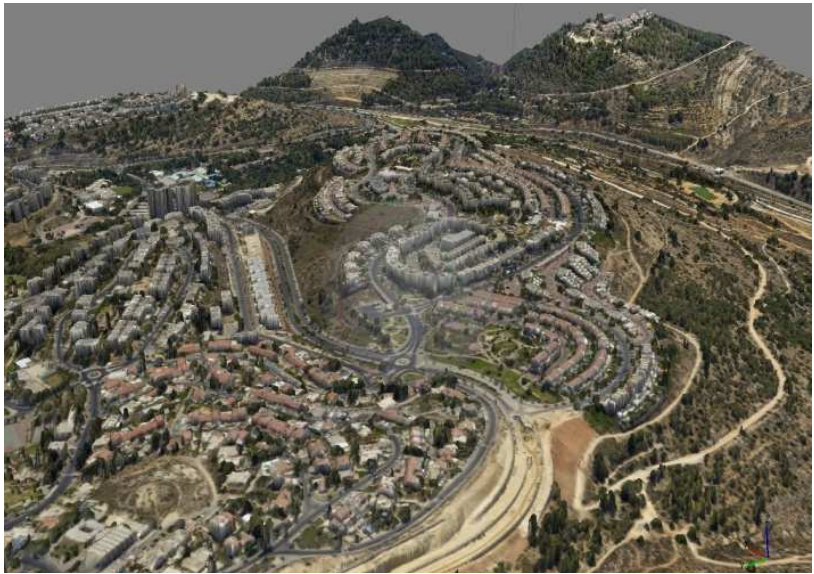

Figure 9: 3D result as coloured point-cloud of the DSM of Jerusalem
The geometric result of this SLR Camera based Oblique Imager is 0.6 pixels, an extremely good result if we are aware that these Cameras are supposed to be non metric even when calibrated and that they use a focal plane shutter that cause some deviations during exposure.

The more precise way is to make use of cameras with medium format sensors and central leaf shutter that capture images with 50-100 MPIX. Not the higher resolution only, also the precise image geometry of such mapping cameras widened the range of using these data for precise mapping and modelling too. The use of such cameras are in the field of precise 3D City models, to generate high dense DSMs with a extreme good high accuracy and a high redundancy of image data in order to texture the facades. A system with 5 mid-format cameras based on the PhaseOne IXA/IXU technology was developed. With an integrated data-unit, a robust and most accurate Sensor is now used for mapping the urban development in Taiwan. 80 MPix for the nadir camera and 4*50 MPix Cameras for the 4 aspects under 40 tilt angles build the basis of this sensor. Camera stability was the goal to achieve high reliable and accurate data for a proper $3 \mathrm{D}$ evaluation. The system was designed in order to fit into a standard gyro- mount in combination with an Applanix Pos AV GPS-IMU System. AeroTopoL is used with its option for oblique mission planning and as FMS. Besides that, calibration of Cameras, offsets, bore side angles and solving floating lever arms was a difficult task in the complex calibration procedure. Finally, a highly accurate and reliable solution was designed.

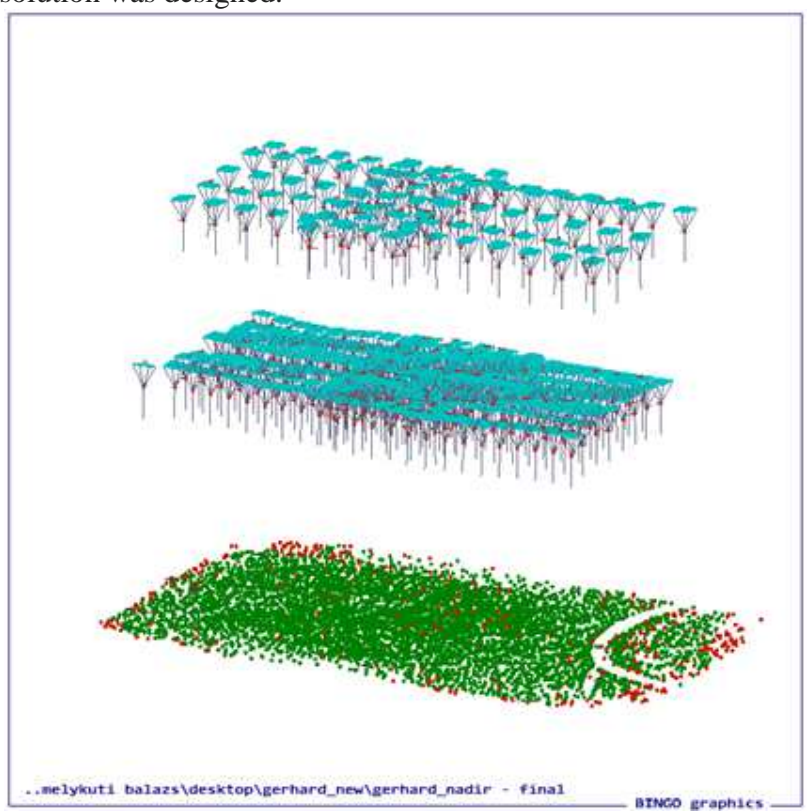

Figure 10: adjustment of the Tie-points during the bundle bock adjustment in Bingo

The aero triangulation results are in the typical metric range of $1 / 3^{\text {rd }}$ of a pixel. The adjustment and use of the external airborne orientation was applied directly to each camera, which means not via the path of co-registration. That way a better accuracy and better error detection is possible.

In Summer 2015, a complex calibration flight on 2 flight levels over the GGS test-field of Speyer was done to validate the camera stability and do the complete calibration process. The results are a calibration of the single cameras, the relative angles 
of the oblique sensors to the nadir one, the absolute borside angles to the IMU and the calibration of the single sensors.

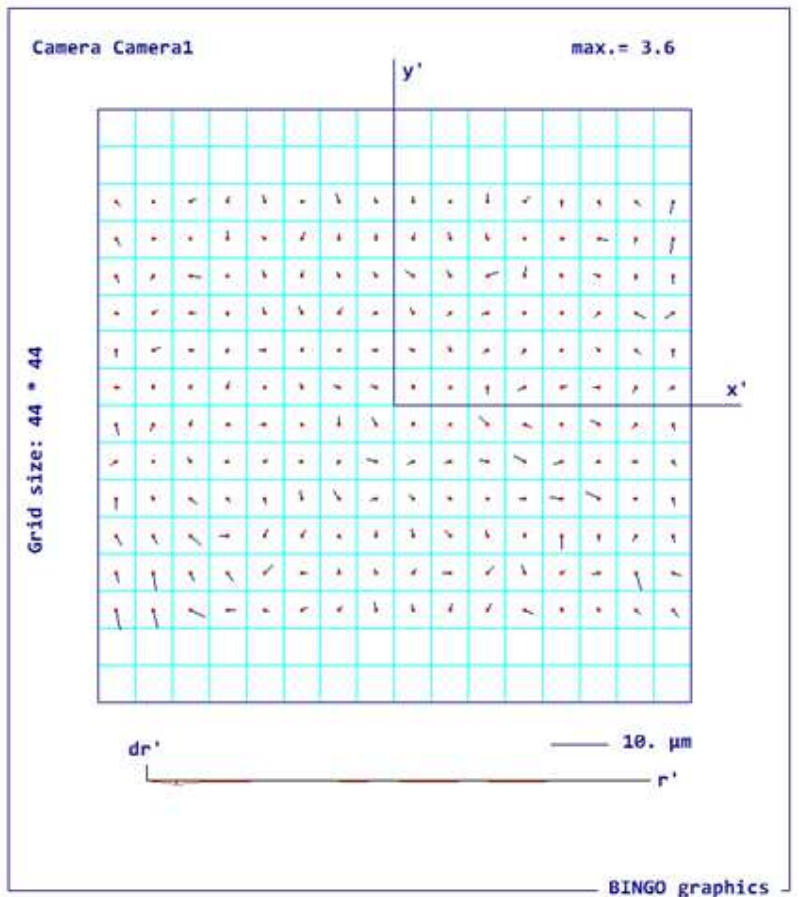

Figure 11: the remaining errors and their directions can be seen on a selected camera.

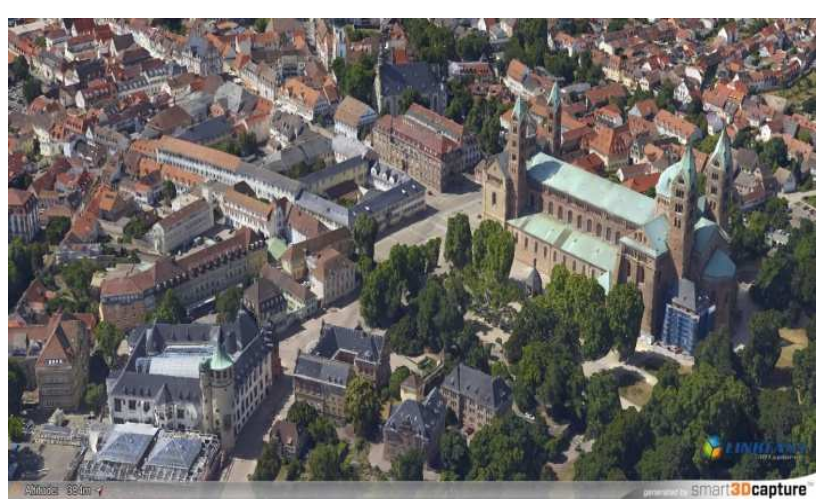

Figure 12: the remaining errors and their directions can be seen on a selected camera

The result has shown that the developed 5head camera is a fully mapping 3D Sensor.

\section{REFERENCES}

VASel, R., KemPer, G., Schuhmann, R., KÖNiger, F. (2008): New airborne Thermal Infrared photogrammetric applications and sensors for moisture detection; Proceedings of the ISPRS Congress 2008 in Beijing.
CAo Li, Li Hongbo, KemPer, G. (2008): Monitoring urban development of small Chinese cities using innovative aerial surveying technologies; Proceedings of the ISPRS Congress 2008 in Beijing

KemPer, G., Li Hongbo, Pauly, K. ${ }^{\dagger}$ (2008): New airborne Sensors and Platforms for specific applications in Photogrammetry and remote sensing; Proceedings of the ISPRS Congress 2008 in Beijing

Hine, D., Kemper, G., Pivnicka, F., Li Hongbo (2008): Innovation in Flight Management Systems using real-time topological GIS Analysis; Proceedings of the ISPRS Congress 2008 in Beijing.

KEMPER, G., VASEL, R. (2009): Luftgestützte Thermographie zur Überwachung von Bauwerksschäden; Innovative Feuchtemessung in Forschung und Praxis 4, Berichtsband zum Workshop 2009, Karlsruhe

Barmettler, A., Nebiker, S., Kemper, G., Koch, C, SchmutZ, M., StUTZ, C., Peter, M., (2010) airAGro -

Fernerkundungslösung für die Agronomie auf der Basis von Leichtflugzeugen und Minidrohnen. 3 Ländertagung der DGPF, OVG und SGPBF Wien.

KEMPER, G. (2010): Neue luftgestützte Sensoren und Plattformen für verschiedenste Aufgaben in der Fernerkundung. 3 Ländertagung der DGPF, OVG und SGPBF, Wien.

Mallast, U., Schwonke, F., Siebert, C., Maraschek, U., KeMPER, G., GeYER, S., KÜHN, F. (2011): Hochauflösende flugzeuggestützte Thermalfernerkundung zur Kartierung submariner und terrestrischer Grundwasserquellen in der hochsalinaren Uferzone des Toten Meeres -

Erste Ergebnisse von Befliegungskampagnen am Westufer des Toten Meeres im Januar 2011:

DGPF Jahrestagung in Mainz 2011

KeMPER, G. (2012): New Airborne Sensors and Platforms for Solving Specific Tasks in Remote Sensing; XXII ISPRS Congress, ISPRS Proceedings, Melbourne/ Australia

KemPer, G., PIVNICKA, F., GeISSLER, S. (2012): Calibration Procedures in Mid Format Camera Setups; XXII ISPRS Congress, ISPRS Proceedings, Melbourne/ Australia.

VASel, R., KemPer, G., Schuhmann, R., KÖNIGER, F. (2012): New airborne thermal infrared photogrammetric applications and sensors for moisture detection; XXII ISPRS Congress, ISPRS Proceedings, Melbourne/ Australia.

Kemper, G. / Schuhmann, R. / Königer, F. (2013): New airbone thermal infrared photogrammetric applications and sensors for moisture detection; Proceedings of the 10th International Conference on Electromagnetic Wave Interaction with Water and Moist Substances (ISEMA), Weimar, 25.-27. September 2013, 423-431. Kupfer, K. [Hrsg.]

Coppack, T., · Weidauer, A., · Kemper, G. (2015): Erfassung von Seevogel- und Meeres-säugerbeständen mittels georeferenzierter Digitalfotografie; AGIT 2015 - Symposium und Fachmesse Angewandte Geoinformatik, At Salzburg, Österreich, Volume: AGIT - Journal für Angewandte Geoinformatik, 1-2015

\footnotetext{
* Corresponding author
} 